\title{
The Mystery of the European Smile: A Comparison Based on Individual Photographs Provided by Internet Users
}

\author{
Piotr Szarota
}

Published online: 11 July 2010

(C) The Author(s) 2010. This article is published with open access at Springerlink.com

\begin{abstract}
The aim of the study was to analyze cross-cultural differences in preference for smiling among the users of one of the most popular instant messaging sites called Windows Live Messenger in terms of facial expression (smiling vs. non-smiling) on the photographs accompanying their profiles. 2,000 photos from 10 countries were rated by two independent judges. Despite the fact that 20 years have passed since the fall of the Berlin Wall, Internet users from a former Soviet bloc appear to smile less often than those from Western Europe. Also, replicating past research, women irrespective of their nationality smiled more than men.
\end{abstract}

Keywords Smiling · Cross-cultural differences · Internet research · Facial expression

The smile is often seen as a universal sign of friendliness or good intentions. People who smile are generally perceived more positively (see Hess et al. 2002); this effect was first reported by Thornton (1943) who found that smiling individuals tend to be rated higher in kindness, honesty, and sense of humor. Numerous studies have found similar effects for other positive personality traits, not only in Western societies like the US (e.g., Reis et al. 1990), Brazil (Otta et al. 1996), or Poland (Szarota 2006), but also in Hong Kong (Lau 1982) and Japan (Matsumoto and Kudoh 1993). The aim of this study was to analyze crosscultural differences in preference for social smiling among the users of one of the most popular instant messaging ${ }^{1}$ sites, Windows Live Messenger.

\footnotetext{
1 Instant messaging is a form of real-time communication between two or more people based on typed text. Windows Live Messenger (formerly known as MSN Messenger, and often referred to as MSN) is available in more than 60 countries and in 26 languages (MSN Internal Data, June 2006). It allows its users to make
}

The author would like to thank Miles Patterson and two anonymous reviewers for helpful comments on previous version of this paper. 
Past research was primarily focused on gender differences in smiling (e.g., DeSantis and Sierra 2000; Morse 1982), and the photographs used in past studies typically came from college yearbooks, with the exception of some experimental studies. In a study by Vrugt and Van Eechoud (2002) subjects imagined that they wanted to obtain a certain part-time job. It appeared that men and women smiled more in response to a low-status job than to a high-status job, moreover women smiled more than men in response to a feminine lowstatus job in which social contacts are important. In another study (Brennan-Parks et al. 1991), subjects were told that their picture would be used in a subsequent facial perception study. This situation was deliberately constructed so that it was ambiguous whether subjects were to smile or not. In fact, there were no sex differences in smiling in sharp contrast to the earlier studies in which subjects were posing for a yearbook or media photograph.

According to Fridlund (1994), a smile usually signifies a readiness to affiliate ("Let's be friends") or to appease ("Whatever you say"). Research suggests that people may trust smiling individuals more than non-smiling individuals. Scharlemann et al. (2001) found in extensive-form bargaining games that photos of smiling individuals are trusted more than those of non-smiling individuals, and in a study by Brown et al. (2003) a smile emerged as a consistent cue to altruism. More recently, Mehu and Dunbar (2008), who conducted a naturalistic observation of people interacting in small groups, demonstrated that smiling as well as laughing is likely to be involved in the formation of cooperative relationships. That effect may be even more pronounced in pre-industrial collectivistic societies (Godoy et al. 2005).

However, there is also evidence pointing to cultural differences in smiling. In Friesen's (1972) classic study, Americans and Japanese viewed emotion eliciting stimuli in two conditions, first alone and then with a higher-status experimenter. In the first condition there were no cultural differences in displays; in the second the Japanese were more likely to mask their negative feelings with smiles. Ekman (1972) interpreted these differences to have occurred because of a Japanese display rule to not show negative emotions to the higher-status experimenter.

Cross-cultural differences in smiling can be also interpreted in terms of nonverbal dialects. Dialect theory (Elfenbein et al. 2007) proposes the presence of cultural differences in the use of cues for emotional expression that are subtle enough to allow accurate communication across cultural boundaries in general, yet substantive enough to result in a potential for miscommunication (Elfenbein and Ambady 2003). Contrary to display rules, nonverbal dialects are subtle variations in the appearance of a display of the same emotion. In their study, Elfenbein et al. (2007) asked participants from Gabon and Quebec in Canada to pose emotional expressions such that "their friends would be able to understand easily what they feel." While posing for happiness, only $27 \%$ of the Gabonese participants in contrast to the majority of Canadians showed a prototypical Duchenne smile, clearly preferring an open-mouthed smile instead.

Last but not least, the cultural assumptions on smiling could be linked to cultural scripts and norms guiding human interaction and self-presentation. As Wojciszke (2004, p. 39) put it recently there are "cultures of affirmation where you must be happy, or at least look so", "keep smiling cultures, where you need not be happy, but you should not be unhappy", and "cultures of complaining where you must be unhappy, or at least look so". The American culture is a perfect example of the first category, and the Polish culture exemplifies the last

Footnote 1 continued

friends with people they find attractive and likeable. The photographs provided by the users accompany personal information such as age, family status, hobbies, etc. 
one. Empirical data shows that while Americans "usually define their mood as better than usual" (cf. Johnson 1937), Poles estimate it on the average as "worse than usual" (Dolinski 1996). There is no doubt that these cultural differences manifest themselves in everyday interaction. However, it is not obvious whether they will affect individuals' choices of photographs of themselves to display on the internet.

Cross-cultural differences in smiling may not only result from cultural, but also from socio-economical factors. Just before the fall of the Berlin wall, Oettingen and Seligman (1990) measured behavioral signs consistent with depression for East and West Berliners in bars, where workmen got together. It appeared that West Berlin workers smiled and laughed significantly more often than those from East Berlin. In West Berlin, the majority of observed men showed upward turned mouths (69\%) and 50\% had upright (as opposed to slumped) posture. Only $23 \%$ of those in East Berlin had their mouths turned upwards, and only $4 \%$ had their bodies upright.

The differences obtained by Oettingen and Seligman (1990) between East and West Berliners reflect a broader divide between East-West countries in Europe on a host of health and well-being factors. Research shows lower life-expectancy and higher suicide rates in former communist countries, compared to those in Western Europe (Makinen 2000), and higher prevalence of depressive symptoms among students from Eastern European countries than among students from Western Europe (Mikolajczyk et al. 2008; Steptoe and Wardle 2001; Wardle et al. 2004). Those differences were typically linked to the political and economic instabilities resulting from political changes in the early 1990s. Also culture-level variables such as GDP, or happiness and life satisfaction indices might be relevant here, and consequently they will be incorporated into the present study.

The context of this research is very different from the one by Oettingen and Seligman (1990). To my knowledge, this is the first study comparing cross-cultural differences regarding self-presentation based on individually selected photographs. It seems plausible that East-West differences in well-being may manifest themselves in spontaneous social interactions, but in regard to self-presentation, when a photograph is being chosen deliberately by a subject for others to see, one could assume more control and impression management. People might look specifically for the photograph on which they are smiling just because (as it was already stated) a smile seems to be a universal sign of friendliness. Would the Europeans really differ in the way they present themselves on MSN or would they rather appear as a single cultural entity? The current study aims to answer this question.

\section{Method}

Sample

MSN classifies the profiles by age and gender; for the purpose of this study, only adults aged 18-39 have been chosen, with males and females equally balanced for each country. I decided to focus on younger adults because they constitute the majority of the users wherever MSN is available (MSN Internal Data, June 2006). It should be noted that a sample of MSN users cannot be considered representative; better educated and wealthier people are usually overrepresented here, especially in the countries with low Internet penetration indices, where Internet access is still perceived as a luxury. This study excluded countries with either very high (e.g., Netherlands-90.1\%) or very low (e.g., Russia-23.2\%) Internet penetration indices according to www.internetworldstats.com 
(updated for June 30, 2008). In the selected countries the Internet penetration indices were moderate and relatively similar, ranging from 41.6 for Poland to 68.6 for Denmark, Finland, and UK.

Data from 10 countries were chosen for further analysis: (a) four countries representing the former Eastern bloc (Czech Republic, Hungary, Poland, and Slovenia); and (b) five Western European countries. Data from Germany was sampled both from the regions of the former German Democratic Republic and from the former West Germany, in the further analysis those regions were classified accordingly as parts of either the former Eastern bloc or Western Europe. 200 photographs (100 males and 100 females) were analyzed per country, resulting in a total of 2,000 .

\section{Categorization of Pictures}

The study was conducted between January 2006 and March 2007. Males' and females' profiles with photographs from the 18-39 age bracket were listed in random order by the MSN searching tool; the first 100 male photos and first 100 female photos in each national sample were chosen for further categorization. In the next step, the photographs were categorized by two independent judges (both Polish nationals), who were asked to decide whether a given picture showed a smile or not. In case of any doubts they were asked to exclude the picture. Raters were unaware of the cultures the photos came from to ensure that they would not be influenced by any personal national stereotypes in their choices.

\section{Results}

Inter-judge agreement turned out to be satisfactory $(r=.91)$. Moreover, intraclass correlations (absolute agreement) were computed; the average measure intraclass correlation coefficient was 0.94 (95\% CI: 0.93-0.95).

A significant difference in the number of smiles in Western and Eastern European samples $\left[\chi^{2}(1, N=2000)=16.63 ; p<.001\right]$ was found, with Eastern Europeans smiling less than Western Europeans (47.5 vs. 56\%). See Table 1 for a listing of the frequency of smiling (overall and by gender) for each country.

In order to directly test the strength of the relationship between the subjective wellbeing and frequency of smiling, a series of Pearson's correlations were conducted. I used the Happiness Index (1997-2007) and Life Satisfaction Index (1997-2007) values reported in a recent meta-analysis by Minkov (2009), along with such measures as Gross Domestic Product per Capita (GDP), and Human Development Index (HDI). Unfortunately, since country is the unit of analysis here, the $N$ s for the correlations are very small. Despite the fact that power for significance testing is very low, the correlations are reported here for exploratory purposes. The correlations between smiles and the culture-level variables were moderate in magnitude: $r(9)=.29$ for the Life Satisfaction Index; $r(9)=.30$ for the Happiness Index; $r(8)=.39$ for HDI; and $r(8)=.42$ for GDP. Again, because of the small sample size, none of these correlations reached conventional levels of significance; however, they were moderate in magnitude and thus provide interesting preliminary findings that should be explored in future research.

Apart from the differences between the Western and Eastern European blocs, there was also considerable variability between countries within blocks, with Poles (39.5\% of smiling 
Table 1 Frequency of smiling by country and gender (Total sample, $N=2000$ )

\begin{tabular}{llllll}
\hline Country & $\begin{array}{l}\text { Smiling overall } \\
(\%)\end{array}$ & $\begin{array}{l}\text { Smiling male } \\
(\%)\end{array}$ & $\begin{array}{l}\text { Smiling female } \\
(\%)\end{array}$ & $\begin{array}{l}\text { Gender differences } \\
\left(\chi^{2}\right)\end{array}$ & $\begin{array}{l}\text { Effect size } \\
(r)\end{array}$ \\
\hline Eastern bloc & 47.5 & 37.6 & 57.4 & $38.52^{* * * *}$ & .21 \\
$\begin{array}{l}\text { Czech } \\
\text { Republic }\end{array}$ & 53.0 & 41.0 & 65.0 & $11.56^{* * *}$ & .24 \\
$\begin{array}{l}\text { Germany } \\
\quad \text { East) }\end{array}$ & 46.0 & 40.0 & 52.0 & 1.45 & .12 \\
Hungary & 45.0 & 39.0 & 51.0 & 2.91 & .12 \\
Poland & 39.5 & 26.0 & 53.0 & $15.25^{* * *}$ & .28 \\
Slovenia & 54.0 & 42.0 & 66.0 & $11.59^{* * *}$ & .24 \\
Western bloc & 56.0 & 46.3 & 65.6 & $45.56^{* * *}$ & .20 \\
Finland & 43.0 & 32.0 & 54.0 & $9.87^{* *}$ & .22 \\
France & 46.5 & 35.0 & 58.0 & $10.63^{* * *}$ & .23 \\
Germany & 47.0 & 42.0 & 52.0 & 1.00 & .10 \\
$\quad$ (West) & & & & & .22 \\
Italy & 61.5 & 48.0 & 75.0 & $15.39^{* * *}$ & .22 \\
Spain & 64.5 & 55.0 & 74.0 & $7.88^{* *}$ & .17 \\
UK & 73.5 & 66.0 & 81.0 & $5.77^{*}$ & \\
\hline
\end{tabular}

$* p<.05 ; * * p<.005 ; * * * p<.001$

faces), Finns (43\%), Hungarians (45\%), and Germans from the former GDR (46\%) appeared to smile the least, while the British $(73.5 \%)$ smiled the most. ${ }^{2}$

There was also a significant gender difference $\left[\chi^{2}(1, N=2000)=83.47 ; p<.001\right]$, with women smiling more often than men (61.5 vs. $41.9 \%)$. These differences have been observed in every culture (for details see Table 1), however, they appeared statistically non-significant in the former West Germany $\left[\chi^{2}(1, N=100)=1.00\right]$, the former GDR $\left[\chi^{2}(1, N=100)=1.45\right]$, and Hungary $\left[\chi^{2}(1, N=200)=2.91\right]$.

\section{Discussion}

As eminent Czech writer, Milan Kundera (2007) once noted "cultural diversity is the great European value...maximum diversity in minimum space" (p. 28). It seems that this diversity might also refer to something as seemingly universal as the smile. The results showed that there was significant difference in preference for smiling between Western Europe and the former communist countries. These differences may be directly influenced by the users' well-being or they may be due to different behavioral strategies.

The first explanation would point to the research by Oettingen and Seligman (1990) and subsequent studies documenting lower indices of subjective well-being and depressive symptoms in Eastern Europe (e.g., Mikolajczyk et al. 2008). In the present study moderate correlations between percentage of smiles and indices of happiness and life satisfaction were recorded.

The second explanation might evoke a concept of post-communist mentality. East Europeans, generally regarded as less assertive, less friendly, and more distrustful, would be less eager to smile than Western Europeans. In her book "Café Europa. Life After

\footnotetext{
${ }^{2}$ Information regarding differences between pairs of individual countries is available on request.
} 
Communism", the Croatian writer Slavenka Drakulic (1997) describes the "non-smiling culture" of Eastern Europe and links it directly to the post-communist mentality: "Here a smile is a sign not of courtesy, but of the inferiority of the smiler ... Not so long ago, a smile could provoke distrust. Why is that person smiling? Does it mean that he or she is happy-how is that possible, with all this misery around us? A show of happiness was a reason to suspect a person-at best it was considered indecent" (p. 50-51).

But differences in smiling might be analyzed apart from the political context. They might stem from deeply embedded cultural values such as sincerity or friendliness. The Polish reserve towards smiling has been quite well documented (Szarota 2006). According to Wierzbicka (1994), one of the core values of the Polish culture is szczeros'ć (roughly, sincerity). The scripts of sincerity concern the value of presenting one's feelings 'truthfully', that is saying, and 'showing' what one really feels, so the smile should always be "felt". There is also some evidence suggesting that Germans (Nees 2000) and French (Carroll 1988; Endy 2003) share a similar attitude.

Another finding points to gender as an even more important predictor of smiling than culture itself. The fact that women tend to smile more often than men has been already well documented (e.g., Hall and Halberstadt 1986). Explaining these differences LaFrance et al. (2003) pointed to the specific requirements of the social roles: women are supposed to be "communal and expressive" and smiling is an effective display for conveying these attributes (p. 325). It should be noted that the task of selecting appropriate photographs for public display may additionally increase concern about behaving in a gender-appropriate way. This effect might be even more pronounced in masculine societies where traditional gender roles are strictly observed; however, the results don't support this assumption. Germany and Hungary, cultures with the least pronounced gender differences in smiling, are classified by Hofstede (2001) as strongly masculine.

\section{Conclusions}

This study was not conducted without limitation. Future research should incorporate data coming from more diverse cultures and go beyond the simple smile/no smile distinction, focusing on more elaborate smile scaling. Ideally, the FACS (Ekman and Friesen 1978) should be used to determine the distribution of Duchenne and non-Duchenne smiles across cultures. If the cultural hypothesis pointing to the value of sincerity in France, Germany, and Poland holds true, users from these countries would show more Duchenne smiles and less non-Duchenne smiles than the users in other countries. Also a bigger sample of countries is needed to better test the subjective well-being hypotheses.

I hope that despite of its shortcomings the present study provide interesting preliminary findings that would be further explored in future research. I also hope that it successfully demonstrated that smiling is a complex social phenomenon which can be explained from different angles, in relation to political systems, economical conditions, well-being, selfpresentation strategies, and, last but not least, as nonverbal behavior guided by specific cultural scripts.

Open Access This article is distributed under the terms of the Creative Commons Attribution Noncommercial License which permits any noncommercial use, distribution, and reproduction in any medium, provided the original author(s) and source are credited. 


\section{References}

Brennan-Parks, K., Goddard, M., Wilson, A. E., \& Kinnear, L. (1991). Sex differences in smiling as measured in a picture taking task. Sex Roles, 24, 375-382.

Brown, W. M., Palameta, B., \& Moore, C. (2003). Are there nonverbal cues to commitment? An exploratory study using the zero-acquaintance video presentation paradigm. Evolutionary Psychology, 1, 42-69.

Carroll, R. (1988). Cultural misunderstandings: French-American experience. Chicago, IL: Chicago University Press.

DeSantis, M., \& Sierra, N. (2000). Women smiled more often and openly than men when photographed for a pleasant public occasion in 20th century United States society. Psychology: A Journal of Human Behavior, 37, 21-31.

Dolinski, D. (1996). The mystery of the Polish soul. B. W. Johnson's effect a rebours. European Journal of Social Psychology, 26, 1001-1006.

Drakulic, S. (1997). Café Europa. Life after communism. New York: Norton.

Ekman, P. (1972). Universal and cultural differences in facial expression of emotion. In J. R. Cole (Ed.), Nebraska symposium on motivation, 1971 (pp. 207-283). Lincoln, NE: Nebraska University Press.

Ekman, P., \& Friesen, W. V. (1978). Facial action coding system: A technique for the measurement of facial movement. Palo Alto: Consulting Psychologists Press.

Elfenbein, H. A., \& Ambady, N. (2003). When familiarity breeds accuracy: Cultural exposure and facial emotion recognition. Journal of Personality and Social Psychology, 85, 276-290.

Elfenbein, H. A., Lavesque, M., Beaupré, M., \& Hess, U. (2007). Toward a dialectic theory: Cultural differences in the expression and recognition of posed facial expressions. Emotion, 7, 131-146.

Endy, C. (2003). Rudeness and modernity. The reception of American tourists in early fifth- republic France. French Politics, Culture \& Society, 21, 55-85.

Fridlund, A. (1994). Human facial expression: An evolutionary view. New York, NY: Academic Press.

Friesen, W. V. (1972). Cultural differences in facial expressions in a social situation: An experimental test of the concept of display rules. Unpublished Doctoral dissertation. San Francisco: University of California.

Godoy, R., Reyes-Garcia, V., Huanca, T., Tanner, S., Leonard, W. R., McDade, T., et al. (2005). Do smiles have a face value? Panel evidence from Amazonian Indians. Journal of Economic Psychology, 26, 469-490.

Hall, J. A., \& Halberstadt, A. G. (1986). Smiling and gazing. In J. S. Hyde \& M. C. Inn (Eds.), The psychology of gender: Advances through meta-analysis (pp. 136-185). Baltimore, MD: Johns Hopkins University Press.

Hess, U., Beaupré, M., \& Cheung, N. (2002). Who to whom and why-cultural differences and similarities in the function of smiles. In M. Abel (Ed.), An empirical reflection on the smile (pp. 187-216). New York, NY: The Edwin Mellen Press.

Hofstede, G. H. (2001). Culture's consequences: Comparing values, behaviors, institutions, and organizations across nations (2nd ed.). Thousand Oaks, CA: Sage Publications.

Johnson, W. B. (1937). Euphoric and depressed mood in normal subjects. Character and Personality, 6, 79-98.

Kundera, M. (2007 Jan 8). Die Weltliteratur. The New Yorker.

LaFrance, M., Hecht, M. A., \& Paluck, E. L. (2003). The contingent smile: A meta-analysis of sex differences in smiling. Psychological Bulletin, 129, 305-334.

Lau, S. (1982). The effect of smiling on person perception. Journal of Social Psychology, 117, $63-67$.

Makinen, I. H. (2000). Eastern European transition and suicide mortalit. Social Science and Medicine, 51, 1405-1420.

Matsumoto, D., \& Kudoh, T. (1993). American-Japanese cultural differences in attributions of personality based on smiles. Journal of Nonverbal Behavior, 17, 231-243.

Mehu, M., \& Dunbar, R. I. M. (2008). Naturalistic observations of smiling and laughter in human group interactions. Behaviour, 145, 1747-1780.

Mikolajczyk, R. T., Maxwell, A. E., El Ansari, W., Naydenova, V., Stock, C., Ilieva, S., et al. (2008). Prevalence of depressive symptoms in university students from Germany, Denmark, Poland and Bulgaria. Social Psychiatry and Psychiatric Epidemiology, 43, 105-112.

Minkov, M. (2009). Predictors of differences in subjective well-being across 97 nations. Cross-Cultural Research, 43, 152-179.

Morse, C. (1982). College yearbook pictures: More females smile than males. Journal of Psychology, 110, 3-6.

Nees, G. (2000). Germany: Unraveling an enigma. Yarmouth, ME: Intercultural Press. 
Oettingen, G., \& Seligman, M. (1990). Pessimism and behavioral signs of depression in East versus West Berlin. European Journal of Social Psychology, 20, 207-221.

Otta, E., Abrosio, F., \& Hoshino, R. (1996). Reading a smiling face: Messages conveyed by various forms of smiling. Perceptual and Motor Skills, 82, 1111-1121.

Reis, H. T., Wilson, I. M., Monestere, C., Bernstein, S., Clark, K., Seidl, E., et al. (1990). What is smiling is beautiful and good. European Journal of Social Psychology, 20, 259-267.

Scharlemann, J. P. W., Eckel, C. C., Kacelnik, A., \& Wilson, R. K. (2001). The value of a smile: Game theory with a human face. Journal of Economic Psychology, 22, 617-640.

Steptoe, A., \& Wardle, J. (2001). Health behaviour, risk awareness and emotional well-being in students from Eastern Europe and Western Europe. Social Science and Medicine, 53, 1621-1630.

Szarota, P. (2006). Psychologia usmiechu. Analiza kulturowa [Psychology of the smile. A cultural analysis]. Gdansk: Gdanskie Wydawnictwo Psychologiczne.

Thornton, G. R. (1943). The effect upon judgments of personality traits of varying a single factor in a photograph. Journal of Social Psychology, 18, 127-148.

Vrugt, A., \& Van Eechoud, M. (2002). Smiling and self-presentation of men and women for job photographs. European Journal of Social Psychology, 32, 419-431.

Wardle, J., Steptoe, A., Gulis, G., Sartory, G., Sęk, H., Todorova, I., et al. (2004). Depression, perceived control, and life satisfaction in university students from Central-Eastern and Western Europe. International Journal of Behavioral Medicine, 11, 27-36.

Wierzbicka, A. (1994). Emotion, language, and cultural scripts. In S. Kitayama \& H. Markus (Eds.), Emotion and culture: Empirical studies of mutual influence (pp. 130-196). Washington, DC: American Psychological Association.

Wojciszke, B. (2004). The negative social world: The Polish culture of complaining. International Journal of Sociology, 34, 38-59. 